\title{
Anti-complement component 5 antibody targeting MG4 domain inhibits choroidal neovascularization
}

\author{
Dong Hyun Jo', ${ }^{1,2}$ Jin Hyoung Kim¹, Wonjun Yang ${ }^{3,4,5}$, Hyori Kim ${ }^{6}$, Shinjae Chang ${ }^{7}$, \\ Dongjo Kim ${ }^{7}$, Minseok Chang ${ }^{7}$, Kihwang Lee ${ }^{8}$, Junho Chung ${ }^{3,4,5}$ and Jeong Hun Kim ${ }^{1,2,9}$ \\ ${ }^{1}$ Fight Against Angiogenesis-Related Blindness (FARB) Laboratory, Clinical Research Institute, Seoul National University \\ Hospital, Seoul, Republic of Korea \\ ${ }^{2}$ Department of Biomedical Sciences and Protein Metabolism, Medical Research Center, Seoul National University College of \\ Medicine, Seoul, Republic of Korea \\ ${ }^{3}$ Department of Biochemistry and Molecular Biology, Seoul National University College of Medicine, Seoul, Republic of Korea \\ ${ }^{4}$ Department of Cancer Biology, Seoul National University College of Medicine, Seoul, Republic of Korea \\ ${ }^{5}$ Cancer Research Institute, Seoul National University College of Medicine, Seoul, Republic of Korea \\ ${ }^{6}$ Asan Institute for Life Sciences, University of Ulsan College of Medicine, Asan Medical Center, Seoul, Republic of Korea \\ ${ }^{7}$ Biotechnology Research Institute, Celltrion, Inc., Incheon, Republic of Korea \\ ${ }^{8}$ Department of Ophthalmology, Ajou University School of Medicine, Suwon, Republic of Korea \\ ${ }^{9}$ Department of Ophthalmology, Seoul National University College of Medicine, Seoul, Republic of Korea \\ Correspondence to: Junho Chung, email: jjhchung@snu.ac.kr \\ Jeong Hun Kim, email: steph25@snu.ac.kr
}

Keywords: age-related macular degeneration, choroidal neovascularization, complement component 5, MG4 domain, therapeutic antibody

Received: January 31, $2017 \quad$ Accepted: March 15, $2017 \quad$ Published: April 19, 2017

Copyright: Jo et al. This is an open-access article distributed under the terms of the Creative Commons Attribution License 3.0 (CC BY 3.0), which permits unrestricted use, distribution, and reproduction in any medium, provided the original author and source are credited.

\section{ABSTRACT}

Age-related macular degeneration (AMD) is one of the main causes of visual impairment in adults. Visual deterioration is more prominent in neovascular AMD with choroidal neovascularization (CNV). Clinical and postmortem studies suggested that complement system activation might induce CNV. In this study, we demonstrated that an anti-mouse complement component 5 (C5) antibody targeting MG4 domain of $\beta$ chain effectively inhibited $C N V$ which was induced by laser photocoagulation in mice. The targeted epitope of this anti-C5 antibody was different from that of currently utilized anti-C5 antibody (eculizumab) in the MG7 domain in which a single nucleotide polymorphism $(\mathrm{R} 885 \mathrm{H} / \mathrm{C})$ results in poor response to eculizumab. Even with targeting MG4 domain, this anti-C5 antibody reduced production of C5a, monocyte chemoattractant protein-1 and vascular endothelial growth factor to prevent infiltration of F4/80-positive cells into CNV lesions and formation of CNV. Furthermore, anti-C5 antibody targeting MG4 domain induced no definite toxicity in normal retina. These results demonstrated that anti-C5 antibody targeting MG4 domain inhibited CNV in neovascular AMD.

\section{INTRODUCTION}

Complement dysregulation induces the pathogenesis of age-related macular degeneration (AMD), the leading cause of blindness in adults over 50 years of age $[1,2]$. One of the most important genetic risk factors in AMD is a polymorphism $(\mathrm{Y} 402 \mathrm{H})$ in the alternative pathway inhibitor, complement factor $\mathrm{H}[3,4]$. In addition, genetic variants in complement component 3 (C3), complement component 2 and complement factor $\mathrm{B}$ are also known to be associated with AMD [5, 6]. In particular, upon the activation of the complement system, activation fragments (for example, $\mathrm{C} 3 \mathrm{a}$ and C5a) can amplify and exacerbate inflammation and tissue injury [7]. In the eye of a patient with AMD, C3a and 
C5a are localized to drusen, the proximity of retinal pigment epithelial (RPE) cells and Bruch's membrane [8]. In line with these results, drusen in the eyes of patients with AMD are immunopositive with complement component 5 (C5) and C5b-9 complex [9] and the C5 components are present in the drusen and RPE cells overlying or directly adjacent to the drusen [10]. In addition, increased plasma levels of $\mathrm{Bb}$, C3a, C4a, and C5a are associated with AMD [11, 12] and the C5-positivity in membranes of choroidal neovascularization (CNV) is linked with the size of CNV [13]. Accordingly, various complement inhibitors were in development for the treatment of AMD [14].

In the C3-C5 axis, potential targets include individual component (for example, C3 and C5), activation fragments (for example, C3a and C5a) and C5 convertases [7]. Among them, C3 and C5 have been targets of therapeutic drugs for the treatment of AMD. POT-4 (Compstatin, Potentia) is a peptide-based drug targeting C3 [15]. On the other hand, ARC1905 (Zimura, Ophthotech), LFG316 (Novartis) and eculizumab (Soliris, Alexion) target C5 $[2,14]$. Because the mechanism how C5 convertases cleave C5 remains elusive, it is important to pinpoint the binding sites of C5-targeting drugs and investigate their biological activities [16]. Furthermore, recent studies emphasized the roles of thrombin, plasmin and human neutrophil elastase other than $\mathrm{C5}$ convertase in the production of activation fragments by the cleavage of C5 [17-19]. These findings added a layer of complexity in the regulation of C5 cleavage for the treatment of complement-related diseases. In addition, the polymorphisms in the target protein might be considered because they can result in poor response to antibodybased treatments, as a genetic variant in MG7 domain of C5 $(\mathrm{R} 885 \mathrm{H})$ attenuates clinical effects of FDA-approved eculizumab [20]. In this context, it is necessary to develop anti-C5 antibody targeting different domains of C5 with effective functional activity.

In this study, we investigated the biological activity of an antibody targeting MG4 domain of murine C5 in a murine model of laser-induced CNV. This model confers an accelerated model of neovascular AMD, demonstrating transition of phases from inflammation to neovascularization [8]. In contrast to eculizumab targeting MG7 domain which inhibits C5 cleavage by the C5 convertase, this antibody might prevent the formation of effector proteins from C5 by other proteases. Nevertheless, our anti-C5 antibody also inhibited CNV, comparable to that of BB5.1, a murine surrogate antibody to eculizumab. This anti-C5 antibody inhibits production of $\mathrm{C} 5 \mathrm{a}$, monocyte chemoattractant protein (MCP)-1 and vascular endothelial growth factor (VEGF) after laser photocoagulation, preventing infiltration of F4/80-positive cells into CNV lesions. Despite excellent therapeutic efficacy, anti-C5 antibody does not induce definite toxicity in normal retina. These results suggest the potential of the newly developed anti-C5 antibody in the treatment of neovascular AMD and further indications.

\section{RESULTS}

\section{Development of an anti-C5 antibody targeting MG4 domain}

An antibody targeting MG4 domain of mouse C5 was developed through immunization, phage-display, and further biopanning using recombinant $\beta$-chain and MG4 domain of mouse C5 (Figure 1A). As shown in Figure $1 \mathrm{~B}, \mathrm{MG} 4$ domain resides in the $\beta$-chain of $\mathrm{C} 5$. In nonreducing and reducing conditions, this anti-C5 antibody effectively recognized whole mouse $\mathrm{C} 5$ and $\beta$-chain of $\mathrm{C} 5$, respectively, from DBA/1 mouse sera (Figure 1C). In reducing condition, $\mathrm{C} 5$ is divided into $\alpha$ - and $\beta$-chain, which are linked to each other with disulfide bonds. Further ELISA analyses showed that anti-C5 antibody specifically bound to recombinant $\beta$-chain and MG4 domain of mouse C5 at sub-nanomolar concentrations (Figure 1D). These results demonstrated that anti-C5 antibody effectively bound to mouse $\mathrm{C} 5$, especially MG4 domain.

\section{Anti-C5 antibody targeting MG4 domain inhibits laser-induced $\mathrm{CNV}$ in mice}

There have been no reports on the functional activity of anti-C5 antibody targeting $\beta$-chain or MG4 domain. To verify the biological activity of anti-C5 antibody targeting MG4 domain, it was injected into the vitreous cavity of mice just after laser photocoagulation. In this mouse model of laser-induced CNV, anti-C5 antibody inhibited the formation of $\mathrm{CNV}$, comparable to that of BB5.1, a murine surrogate antibody to eculizumab (Figure 2A and 2B). In contrast, there was no definite anti-angiogenic activity with delayed injection of anti-C5 antibody 4 days after laser photocoagulation (Figure 2C), indicating that there might be time-dependent action of anti-C5 antibody.

\section{Anti-C5 antibody reduces production of C5a, MCP-1 and VEGF after laser photocoagulation}

A laser-induced CNV model in mice is an accelerated model of neovascular AMD [8]. Laser photocoagulation not only induces a break in Bruch's membrane but also invokes inflammatory cascades to promote the growth of new vessels [21, 22]. As in a previous report [8], C5a was increased 6 hours after laser photocoagulation (Figure 3A and Supplementary Figure 1A). The peaks of levels of MCP-1 and VEGF were evident at 12 hours and 3 days after laser photocoagulation, respectively (Figure 3B and $3 \mathrm{C}$; Supplementary Figure 1B and 1C). Cytokine arrays of 40 different cytokines also demonstrated that sequential elevation of C5a ( 6 hours) and MCP-1 (24 hours) in RPEchoroid-scleral complexes after laser photocoagulation (Figure 3D).

Anti-C5 antibody, when administered intravitreally just after laser photocoagulation, effectively inhibited 
the sequential increase in the production of $\mathrm{C} 5 \mathrm{a}$, MCP1 and VEGF (Figure 3A-3C). Upon activation of the complement system, C5 is cleaved into C5a and C5b. RPE cells are known to increase the expression of various inflammatory cytokines on C5a stimulation [23, 24]. In lines with these results, C5a treatment increased the expression of CCL2 mRNA (Figure 3E) and the secretion of MCP-1 into the media (Figure 3F) in ARPE-19 cells grown as confluent cells. These results supported the data on production of $\mathrm{C} 5 \mathrm{a}$ and $\mathrm{MCP}-1$ in vivo.

\section{Anti-C5 antibody prevents infiltration of F4/80-positive cells in CNV lesions}

As macrophage infiltration is observed in human CNV samples [13, 25], macrophages infiltrate into $\mathrm{CNV}$ lesions in a murine laser-induced CNV model and the degree of macrophage infiltration peaks at 3 days after laser photocoagulation [8, 26-28]. The infiltrated macrophages evolve to display VEGF expression [29] and are polarized to pro-angiogenic M2-type [30, 31]. Upon the treatment with anti-C5 antibody, the degree of infiltration of F4/80-positve cells was significantly decreased at 3 days after laser photocoagulation (Figure $4 \mathrm{~A}$ and $4 \mathrm{~B})$. As in a previous report on the use of antibodies to C3a and C5a [8], anti-C5 antibody effectively attenuated the first (day 1) and second (day 3) increase of VEGF in a murine laser-induced CNV model (Figure 3C and Supplementary Figure 1C). The first increase in VEGF might be due to from resident cells including RPE [8], as $\mathrm{C} 5 \mathrm{a}$ induced increased expression and secretion of VEGF in RPE cells (Supplementary Figure 2A and 2B). On the other hand, the second surge might be due to infiltrated macrophages, as they exhibit pro-angiogenic properties with VEGF expression [28-31].

\section{Anti-C5 antibody does not induce definite toxicity in the normal retina}

In the development of therapeutic agents for retinal diseases, it is important to consider potential toxicity on the normal retina not to affect the vision $[32,33]$. To investigate the potential toxicity of anti-C5 antibody to the normal retina, gene expression microarray was performed using the retinal samples prepared 7 days after the treatment with anti-C5 antibody at the therapeutic dose $(1 \mu \mathrm{g}$ per eye; Figure $5 \mathrm{~A}$ and Supplementary Table 1) and 10 times the therapeutic dose (10 $\mu \mathrm{g}$ per eye; Figure 5B and Supplementary Table $2)$. There were 5 and 68 differentially expressed genes (fold change $>2$ and $P$-value $<0.05$ ) upon treatment with anti-C5 antibody at the therapeutic and 10 times the therapeutic doses, respectively. In addition, there were no definite changes in histologic integrity of the
A

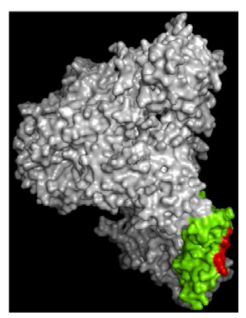

C

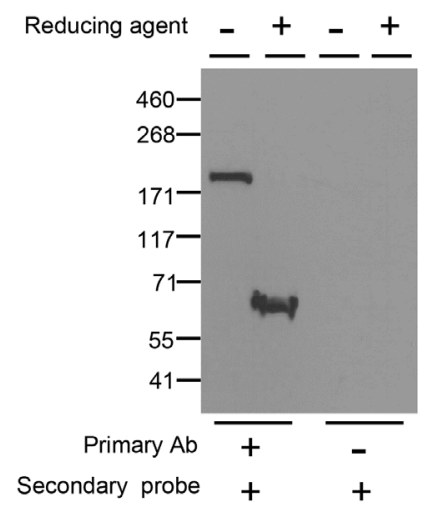

B
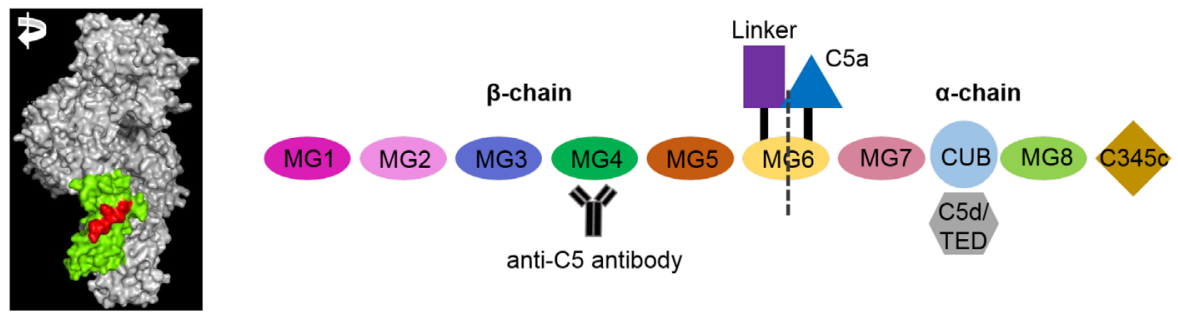

D

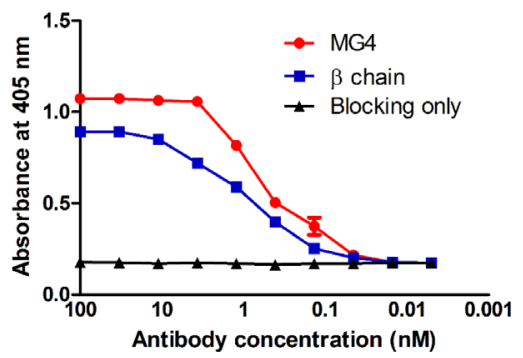

Figure 1: Development of anti-C5 antibody targeting MG4 domain. (A) 3-D structure of C5 (Reference PDB 3CU7). MG4 domain and binding epitope of anti-C5 antibody were identified in green and red, respectively. (B) Schematic diagram of mouse C5 with anti-C5 antibody. (C) Western blot analyses of serum of DBA/1 mouse with anti-C5 antibody in non-reducing and reducing conditions. Representative figures from 3 independent experiments. (D) Binding affinity of anti-C5 antibody to MG4 domain and $\beta$-chain of mouse C5 on ELISA $(n=6)$. 
retinal layers, the total thickness of retinal layers (Figure 5C and Supplementary Figure 3) and apoptotic activity measured by the level of cleaved caspase-3 (Figure 5D) at 7 days after the treatment of anti-C5 antibody at 10 times the therapeutic dose. Neither cellular toxicity was observed in murine brain microvascular endothelial cells with the treatment of anti-C5 antibody at the concentrations from $1 \mathrm{ng} / \mathrm{mL}$ to $1 \mu \mathrm{g} / \mathrm{mL}$ in WST- 1 assay (Figure 5E) and direct cell counting with methylene blue staining (data not shown).

\section{DISCUSSION}

In this study, an anti-C5 antibody targeting MG4 domain effectively inhibited $\mathrm{CNV}$ in a mouse model of CNV, a well-established animal model of neovascular AMD [21]. This model demonstrates representative characteristics of neovascular AMD including the involvement of complement system, infiltration of immune cells, and CNV [8-10, 13, 25-31]. Upon laser photocoagulation to Bruch's membrane delineating RPE and choroid, the complement system is activated in response to tissue damage and exacerbates inflammation and tissue injury as in other organs [7]. In particular, as C5 and its cleaved forms of effector proteins (C5a and C5b) are expressed in human $\mathrm{CNV}[8,9,13]$ and associated with the progression of neovascular AMD $[12,13]$, C5a is elevated in RPE-choroid-scleral complexes [8] and the level of C5a is related with the degree of CNV formation in the laser-induced CNV model in mice [34]. In this study, we also demonstrated that C5a was elevated in RPE-choroid-scleral complexes, of which the highest value was evident at 6 hours after laser photocoagulation (Figure 3A and Supplementary Figure 1A).

The involvement of $\mathrm{C} 5$ and its cleaved effector proteins in the pathogenesis of CNV might be considered in 2 distinct phases. First, C5a directly affects RPE cells to express and secrete VEGF in vitro and in vivo $[8,35$, 36]. This phenomenon was confirmed using quantitative real-time polymerase chain reaction and ELISA in this study (Supplementary Figure 2A and 2B). Second, C5a attracts immune cells including macrophages by inducing the expression and secretion of cytokines such as MCP1 and granulocyte-macrophage colony-stimulating factor (GM-CSF) [23, 37]. In a study using a primary human RPE cell line and ARPE-19 cells which possess C5a receptors, C5a increases the expression of interleukin 6, MCP-1, and GM-CSF [23]. Similarly, C5a induced

A

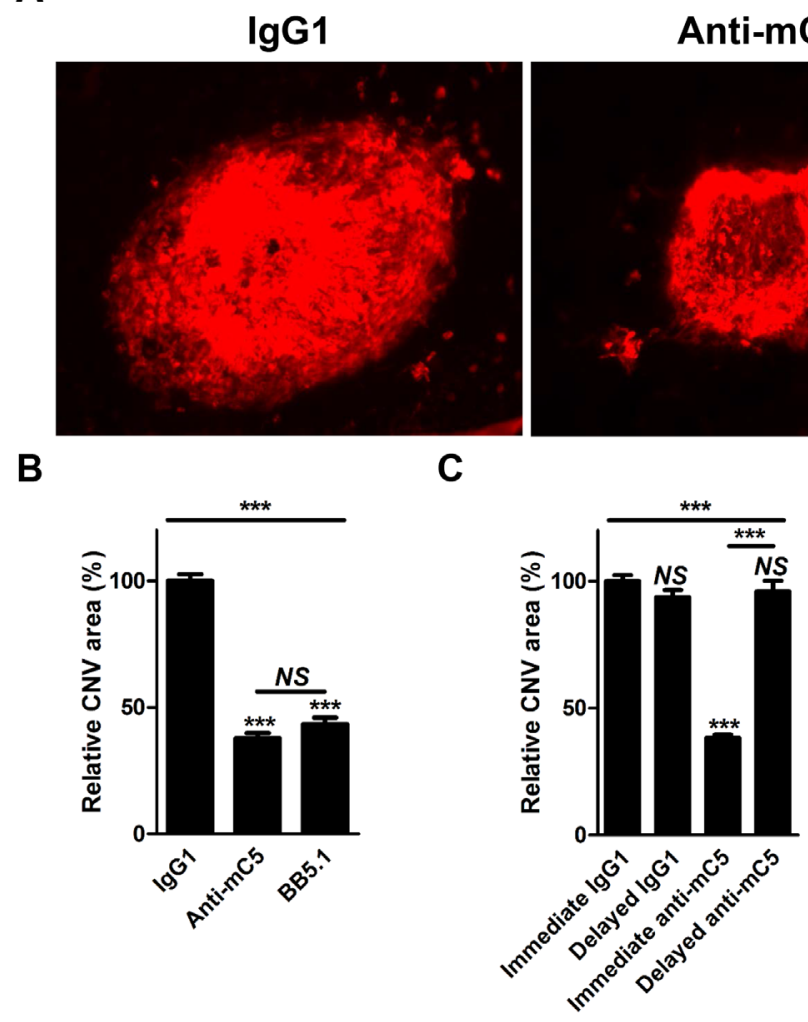

Figure 2: Anti-C5 antibody targeting MG4 domain inhibits laser-induced CNV in mice. (A) Representative photographs of $\mathrm{CNV}$ at 7 days after laser photocoagulation and intravitreal injection of IgG1 isotype control, anti-C5 antibody, or BB5.1 demonstrated by immunostaining with isolectin B4-594. Scale bar, $200 \mu \mathrm{m}$. (B) Quantitative demonstration of relative CNV areas regarding Figure 2A $(n=$ 12). (C) Quantitative demonstration of relative CNV areas at 7 days after laser photocoagulation. 'Immediate' and 'Delayed' indicate that antibodies were injected just after laser photocoagulation and 4 days later, respectively $(n=12)$. Anti-mC5, anti-C5 antibody; IgG1, IgG1 isotype control. NS, P-value $>0.05$; ***, P-value $<0.001$ (Kruskal-Wallis test with post-hoc Dunn's multiple comparison test). 
A

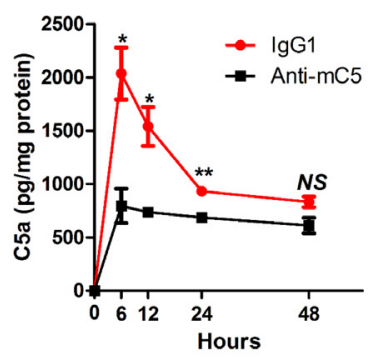

D

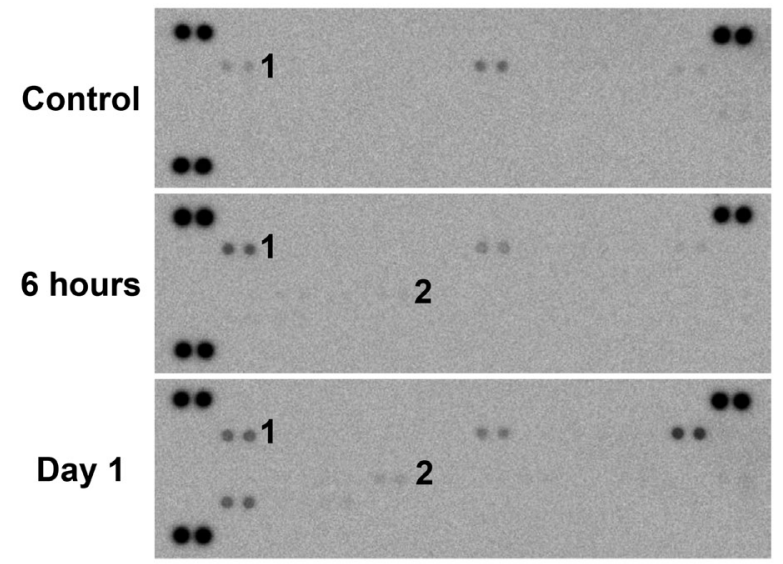

1: $\mathrm{C} 5 / \mathrm{C} 5 \mathrm{a}$

2: MCP-1

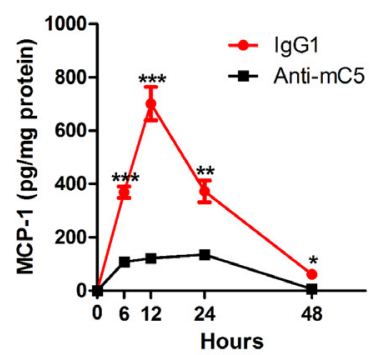

E

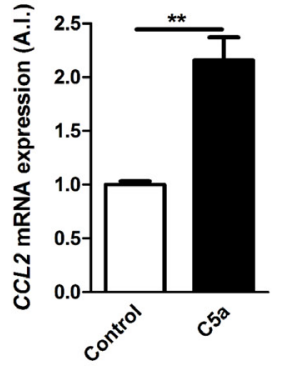

$\mathbf{F}$

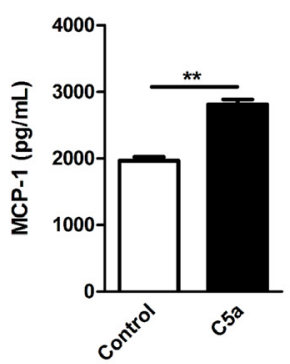

Figure 3: Anti-C5 antibody reduces sequential expression and secretion of C5a, MCP-1, and VEGF after laser photocoagulation. (A-C) The levels of C5a (A), MCP-1 (B), and VEGF (C) in RPE-choroid-scleral complexes $(n=6)$. The extended versions of the graphs are provided in Supplementary Figure 1. (D) The patterns of multiple cytokines in RPE-choroid-scleral complexes after laser photocoagulation. Representative figures from 3 independent experiments. (E) Relative CCL2 mRNA expression according to the treatment with C5a in ARPE-19 cells $(n=6)$. (F) Amounts of VEGF in conditioned media according to the treatment with C5a $(n=6)$. Anti-mC5, anti-C5 antibody; IgG1, IgG1 isotype control. NS, P-value $>0.05$; *, P-value $<0.05$; **, P-value $<0.01$; ***, P-value $<0.001$ (Mann-Whitney U-test).

A

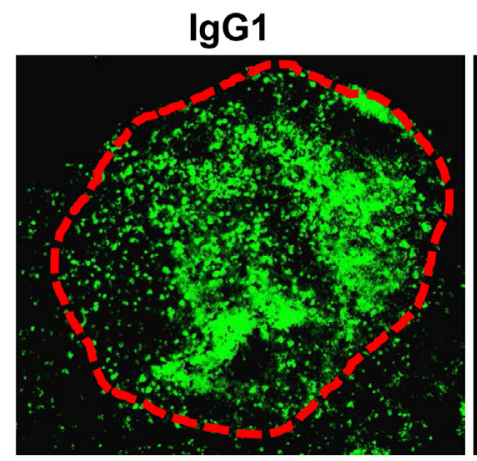

Anti-mC5

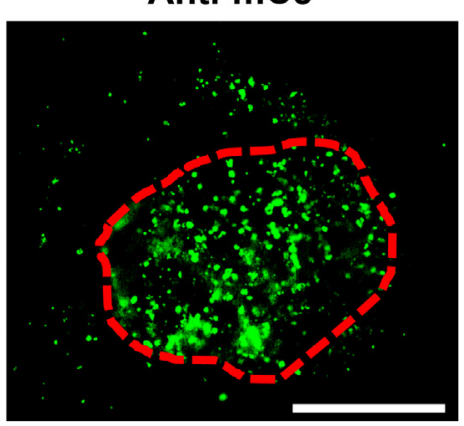

B

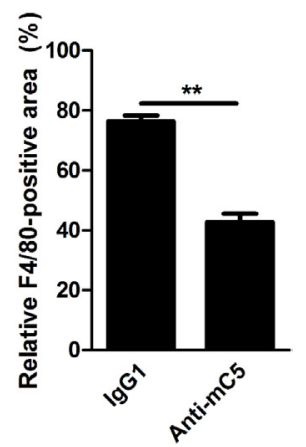

Figure 4: Anti-C5 antibody prevents infiltration of F4/80-positive cells in CNV lesions. (A) Representative photographs of F4/80-positive cells in CNV lesions at 3 days after laser photocoagulation and intravitreal injection of anti-C5 antibody. Red dashed lines delineate CNV areas. Scale bar, $200 \mu \mathrm{m}$. (B) Quantitative analyses of relative F4/80-positive areas of CNV lesions $(n=6)$. Anti-mC5, anti-C5 antibody; IgG1, IgG1 isotype control. **, P-value < 0.01 (Mann-Whitney U-test). 
A

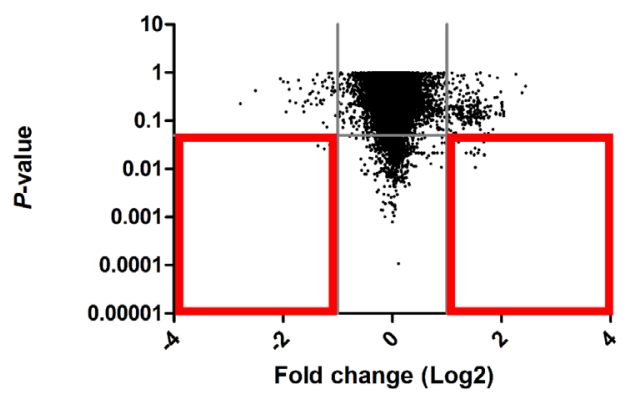

C

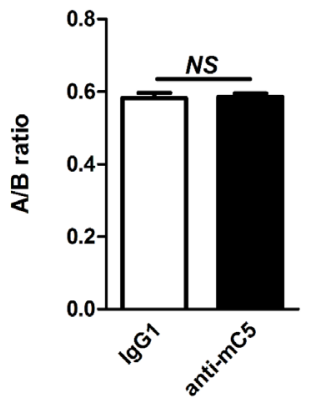

B

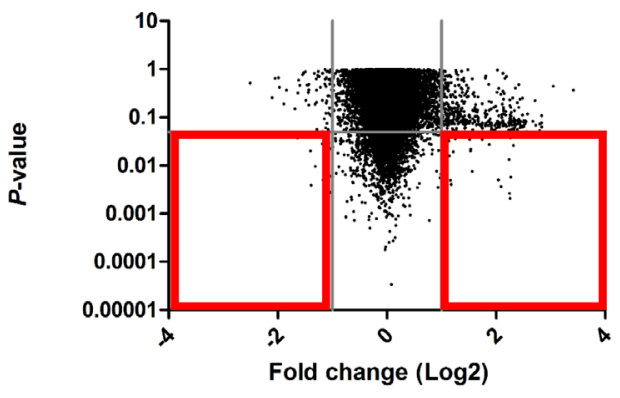

$\mathbf{E}$

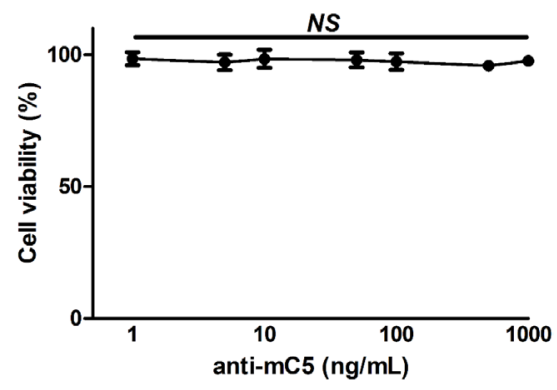

Figure 5: Anti-C5 antibody does not induce definite toxicity in the normal retina. (A and B) Gene expression profiles in the retina at 7 days after intravitreal injection of (a) $1 \mu \mathrm{g}$ and (b) $10 \mu \mathrm{g}$ of anti-C5 antibody. Red boxes indicate differentially expressed genes of which fold changes were over 2 and P-values were less than 0.05. (C) The ratios ("A/B ratio") of retinal thickness of the inner retina (from the internal limiting membrane to the inner nuclear layer, "A") to the whole retina (from the internal limiting membrane to the outer nuclear layer, "B") according to the treatment with IgG1 isotype control or anti-C5 antibody $(n=6)$. (D) Relative amounts of cleaved caspase-3 in the retina according to the treatment with IgG1 isotype control or anti-C5 antibody $(n=6)$. (E) Relative cell viability of bEnd.3 cells with the treatment of anti-C5 antibody at varying concentrations $(n=6)$. Anti-mC5, anti-C5 antibody; IgG1, IgG1 isotype control. NS, P-value $>0.05$ (Mann-Whitney U-test in Figure 5C and 5D; Kruskal-Wallis test and post-hoc Dunn's multiple comparison test in Figure 5E).

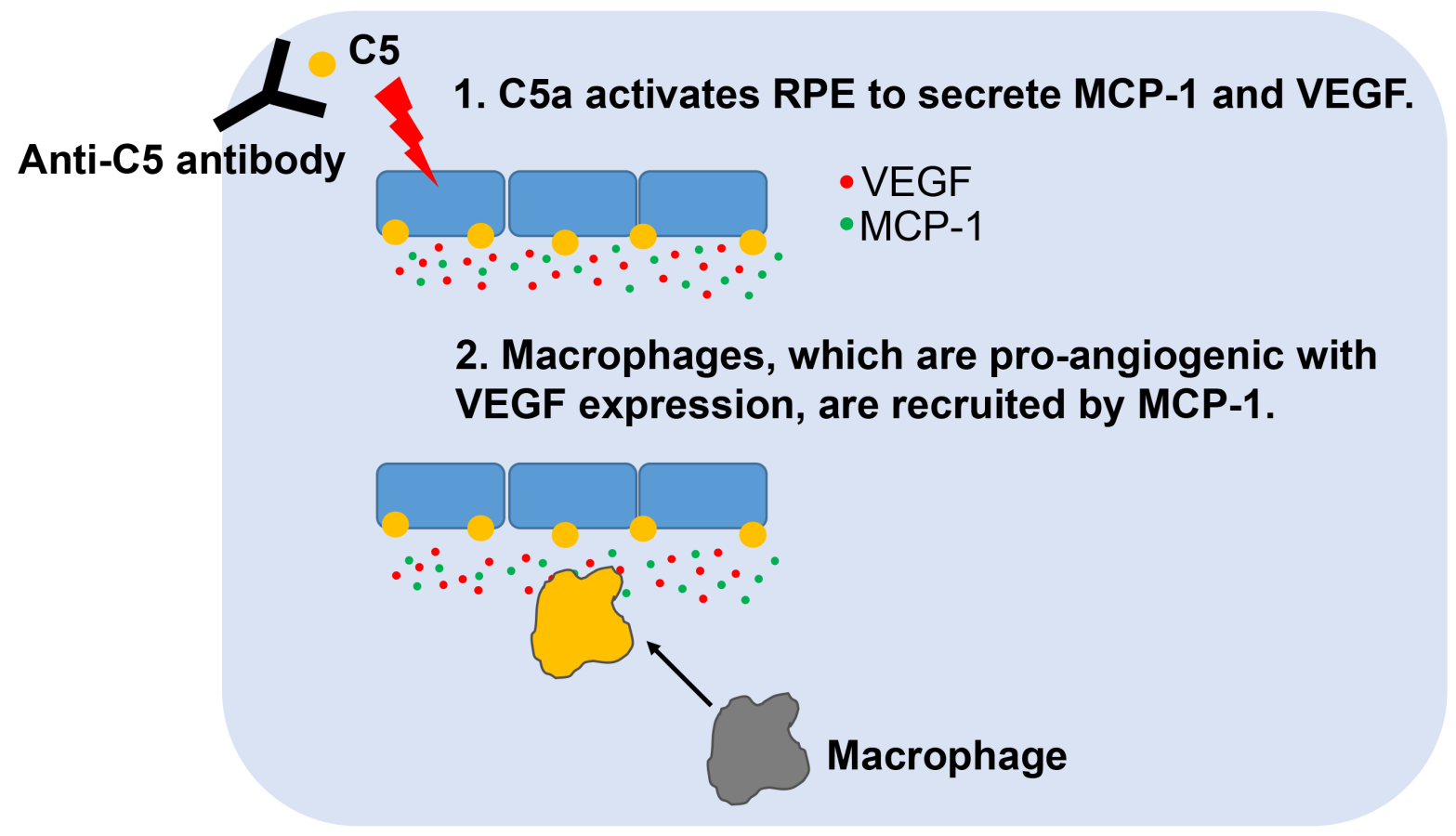

Figure 6: Schematic summary of the mode of action of anti-C5 antibody in the inhibition of CNV. 
the expression and secretion of MCP-1 in ARPE-19 cells (Figure 3E and 3F) and the peak of MCP-1 level was evident at 12 hours after laser photocoagulation, following that of $\mathrm{C} 5 \mathrm{a}$, in the laser-induced $\mathrm{CNV}$ model in mice (Figure 3B and 3D; Supplementary Figure 1B). Furthermore, C5a activates the expression of intercellular adhesion molecule-1 in human choroidal and umbilical vein endothelial cells, which promotes the recruitment of monocytes/macrophages [38, 39]. Macrophages which are recruited in this way demonstrate pro-angiogenic properties, including the expression of VEGF, with the increased expression of markers of M2-type macrophages $[30,31,40]$. In this context, CNV was inhibited with C5 and $\mathrm{C} 5 \mathrm{a}$ targeting approaches in the laser-induced CNV model in mice [8, 41-43]. In this study, anti-C5 antibody inhibited the formation of $\mathrm{CNV}$ with the attenuation of sequential production of C5a, MCP-1, and VEGF. Based on these results, the dynamic mechanism of action of anti-C5 antibody could be established (Figure 6). Anti-C5 antibody targeting MG4 domain bound to C5 and inhibited the cleavage of it to C5a and C5b. In this manner, the antibody prevented the activation of RPE to secrete VEGF (related with the first surge of VEGF in a laser-induced CNV model) and MCP-1, which attracts VEGF-expressing macrophages to the $\mathrm{CNV}$ lesions (related with the second surge of VEGF).

It is also remarkable that the inhibition of $\mathrm{C} 5$ mediated process was accomplished by anti-C5 antibody targeting MG4 domain in $\beta$-chain of C5. The currently utilized anti-C5 antibody in paroxysmal nocturnal hemoglobinuria, eculizumab, targets MG7 domain in $\alpha$-chain, preventing the interactions between $\mathrm{C} 5$ and $\mathrm{C} 5$ convertases [16, 44, 45]. Despite its clinical success, the $\mathrm{R} 885 \mathrm{H} / \mathrm{C}$ mutation which is evident in $3.2-3.5 \%$ of Japanese population [20] disrupts the eculizumab epitope and is associated with poor response to eculizumab. Although the exact roles of MG4 domain in the production of active fragments are yet to be established, MG4 domain targeting might intervene the cleavage of $\mathrm{C} 5$ by proteases including thrombin, plasmin, and human neutrophil elastase other than C5 convertase. Inhibition via mechanically distinct strategies against C5 potentially allow fine-tuning of therapeutic effects from the regulation of C5 cleavage [16].

In conclusion, our anti-C5 antibody inhibited the formation of $\mathrm{CNV}$ by binding to MG4 domain of $\mathrm{C} 5$ and subsequently preventing $\mathrm{C} 5$ to be cleaved to effector proteins. Targeting the specific epitope in $\beta$-chain of $\mathrm{C} 5$ with sufficient biological activity confers a way to bypass resistance to ones targeting MG7 domain including Arg885 where single nucleotide polymorphism occurs at $~ 3 \%$ of the Asian population. Furthermore, with targeting to $\mathrm{C} 5$ in the complement system, anti-C5 antibody effectively inhibited the expression and secretion of VEGF from RPE and the infiltration of pro-angiogenic macrophages into CNV lesions, preventing the growth of CNV. This study suggested that anti-C5 antibody targeting MG4 domain might exert effective therapeutic activity against CNV and could be a valuable armamentarium against wet AMD.

\section{MATERIALS AND METHODS}

\section{Development of an anti-C5 antibody targeting MG4 domain}

Total RNA was prepared using TRI reagent (Invitrogen) form spleen, bone marrow and bursa of Fabricius of white leghorn chickens which had been immunized against MG4 domain and $\beta$-chain of mouse C5. First-strand cDNA was synthesized using superscript reverse transcriptase with oligo (dT) priming (Invitrogen). Using this cDNA, a phage-display library of rabbit singlechain variable fragment ( $\mathrm{scFv}$ ) was constructed using pComb3XSS phagemid vector as previously described $[46,47]$. After the library construction, $\mathrm{scFv}$ clones were selected from the library through five rounds of biopanning as described previously [46]. For each round of biopanning, $1.5 \mu \mathrm{g}$ of mouse MG4 domain and $\beta$-chain protein coated magnetic beads (Dynabeads M-270 Epoxy; Invitrogen) were used. The anti-mouse C5 antibody is chimeric antibody containing chicken $\mathrm{scFv}$ and murine IgG1 of which heavy chain and light chain were subcloned into the pCT184 and pCT146, respectively. These vectors were co-transfected to Chinese hamster ovary-K1 cells and the supernatant was subjected to protein G affinity gel chromatography for purification. This process of antibody production was supported by Celltrion.

\section{Western blot analysis}

DBA/1 mouse sera were diluted 1/10 with PBS and electrophoresed under reducing and non-reducing conditions in a SDS-PAGE gel (NuPAGE 3-8\% TrisAcetate, Invitrogen) and transferred to a nitrocellulose membrane (Whatman) as reported previously [48]. The membrane was blocked with 5\% skim milk with PBS containing $0.02 \%$ Tween-20 (Sigma) for 1 hour at room temperature (RT) and then incubated with $5 \mu \mathrm{g} / \mathrm{ml}$ of anti-C5 $\mathrm{x}$ anti-cotinine bispecific tandem scFv-human Fc fusion protein overnight at $4{ }^{\circ} \mathrm{C}$. The blots were washed with PBS containing $0.02 \%$ Tween-20 five times and incubated with $1 \mu \mathrm{g} / \mathrm{ml}$ of cotinine-horseradish peroxidase for 2 hours at RT. The blots were visualized as described previously [49].

\section{ELISA for the measurement of binding affinity of anti-C5 antibody to $\mathrm{C5}$}

The half-well ELISA plates (Corning) were coated with $100 \mathrm{ng}$ of mouse C5 $\beta$ chain and MG4 domain proteins with ckappa-tag overnight at $4^{\circ} \mathrm{C}$. The wells were blocked with $150 \mu \mathrm{L}$ of $3 \% \mathrm{BSA}$ in PBS (w/v) for 
1 hour at $37^{\circ} \mathrm{C}$. The plates were washed with $150 \mu \mathrm{L}$ of PBS containing $0.05 \%$ Tween-20. $1 \mu \mathrm{M}$ of anti-C5 antibody 1:3 serially diluted with $3 \% \mathrm{BSA}$ in $\mathrm{PBS}(\mathrm{w} / \mathrm{v})$ and incubated at $37^{\circ} \mathrm{C}$ for 2 hours. After washing with 150 $\mu \mathrm{L}$ of PBS containing $0.05 \%$ Tween-20 three times, $50 \mu \mathrm{L}$ of horseradish peroxidase-conjugated goat anti-mouse IgG (Fc) antibody (Sigma, A0168) diluted in blocking buffer $(1: 5,000)$ was added to each well and incubated for 1 hour at $37^{\circ} \mathrm{C}$. After repeated washing three times, $1 \mu \mathrm{g} / \mathrm{ml}$ of 2, 2'-azino-bis(3-ethylbenzothiazoline-6-sulphonic acid) (Amresco) in $0.05 \mathrm{M}$ citric acid buffer $(\mathrm{pH} 4.0)$ and $1.0 \%$ $\mathrm{H}_{2} \mathrm{O}_{2}$ were added to each well, and the optical density was measured at $405 \mathrm{~nm}$.

\section{Mice}

6-week-old male C57BL/6J mice were purchased from Central Laboratory Animal and then maintained in a specific pathogen free facility in Seoul National University. All animal experiments were performed in accordance with the Association for Research in Vision and Ophthalmology statement for the use of animals in ophthalmic and vision research and all the procedures regarding animal experiments were approved by the Institutional Animal Care and Use Committee of Seoul National University.

\section{Laser-induced choroidal neovascularization in mice}

After deep anesthesia with zolazepam plus tiletamine $(3.75 \mathrm{mg} / \mathrm{Kg}$, Virbac) and xylazyine $(7.5 \mathrm{mg} /$ $\mathrm{Kg}$, Bayer), mice were treated with a customized laser indirect ophthalmoscope system (ILOODA) to induce the rupture of Bruch's membrane ( $300 \mu \mathrm{m}$ spot size, 300 $\mathrm{mW}$ power, and $100 \mathrm{~ms}$ exposure time). After the laser photocoagulation, IgG1 isotype control (cat. no. sc3877, Santa Cruz; $1 \mu \mathrm{g} / 1 \mu \mathrm{L})$, anti-C5 antibody $(1 \mu \mathrm{g} / 1 \mu \mathrm{L})$, or BB5.1 (Hycult; $1 \mu \mathrm{g} / 1 \mu \mathrm{L}$ ) was intravitreally administered to 12 mice per each group. For the evaluation of the effects of anti-C5 antibody on CNV, the enucleated eyes were prepared for the isolation of RPE-choroid-scleral complexes at 7 days after the laser photocoagulation. After immunostaining of RPE-choroid-scleral complexes with isolectin B4-594 (1:100; cat. no. I21413, Invitrogen), CNV was quantitatively analyzed by the measurement of the area using the ImageJ program (NIH). The absolute CNV area of IgG1-treated group $(n=6)$ was measured to be $0.15 \pm 0.01 \mathrm{~mm}^{2}$.

\section{Protein preparation from RPE-choroid-scleral complex of mice}

The enucleated eyes were prepared for the isolation of RPE-choroid-scleral complexes at designated time points. Then, RPE-choroid-scleral complexes from mice were put into microcentrifuge tubes $500 \mu \mathrm{L}$ PBS containing protease inhibitor cocktail. After sonication, the tubes were centrifuged $(15,000 \mathrm{rpm}, 15$ minutes $)$ to obtain supernatants.

\section{ELISA for the measurement of murine C5a, MCP-1, and VEGF}

ELISA was performed with corresponding kits for murine C5a (cat. no. EKU03407, Biomatik), MCP-1 (cat. no. MJE00, R\&D), and VEGF (cat. no. MMV00, R\&D) for the measurement of each factor in extracted proteins from the RPE-choroid-scleral complexes according to the manufacturer's instructions.

\section{Cytokine array}

Equal amount of proteins $(200 \mu \mathrm{g})$ prepared from the RPE-choroid-scleral complex was utilized for the measurement of the levels of cytokines using Proteome Profiler ${ }^{\mathrm{TM}}$ Mouse Cytokine Array Panel A (cat. no. ARY006, R\&D), according to the manufacturer's instructions.

\section{Cells}

ARPE-19 cells (cat. no. CRL-2302, ATCC) were maintained in DMEM:F12 supplemented with 10\% fetal bovine serum and 1\% penicillin-streptomycin. bEnd.3 cells (cat. no. CRL-2299, ATCC) were maintained in DMEM supplemented with $10 \%$ fetal bovine serum and $1 \%$ penicillin-streptomycin. All cells were kept in a humidified incubator at $37^{\circ} \mathrm{C}\left(95 \%\right.$ air and $\left.5 \% \mathrm{CO}_{2}\right)$. To monitor the responses of ARPE-19 cells to C5a, the cells grown as confluent cells were treated with human C5a (cat. no. 2037-C5-025/CF, R\&D) for 72 hours after 24 hours of serum deprivation.

\section{ELISA for the measurement of human MCP-1 and VEGF}

ELISA was performed with corresponding kits for human MCP-1 (cat. no. KHC1012, Life Technologies) and VEGF (cat. no. KHG0112, Life Technologies) for the measurement of MCP-1 and VEGF in conditioned media according to the manufacturer's instructions.

\section{Real-time PCR}

Total RNA was isolated from cells using TRI Reagent (Molecular Research Center). Then, the cDNA was prepared with High Capacity RNA-to-cDNA kit (Life Technologies). Real-time PCR was performed with TaqMan $^{\circledR}$ fast advanced master mix (Life Technologies) and Gene Expression Assays (cat. no. 4331182, Life Technologies). Product IDs of specific Gene Expression Assays for CCL2, VEGF, GAPDH, and $18 S$ were 
Hs00234140_m1, Hs00900055_m1, Hs99999905_m1, and Hs99999901_s1. Real-time PCR was performed using StepOnePlus RT-PCR System (Life Technologis) and the results were analyzed with accompanying StepOne Software (ver. 2.2). All procedures were in accordance with MIQE guidelines.

\section{Gene expression microarray}

Mice $(n=12)$ were treated with intravitreal injection of IgG1 isotype $(1 \mu \mathrm{g} / 1 \mu \mathrm{L}$ PBS $)$ or anti-C5 antibody ( 1 or $10 \mu \mathrm{g} / 1 \mu \mathrm{L}$ PBS). At 7 days after the injection, retinas were prepared from the enucleated eyes. Four retinas from 4 mice were put into a microcentrifuge tube for further analyses. For each condition, 3 biological replicates were prepared including 12 retinas. Total RNA was isolated using TRI Reagent (Molecular Research Center). The RNA quality was assessed by Agilent 2100 bioanalyzer using the RNA 6000 Nano Chip (Agilent) and the quantity was determined by ND-2000 Spectrophotometer (Thermo). Equal amounts of total RNA (300 ng) from each sample was converted to double-stranded cDNA. Using a random hexamer incorporating a $\mathrm{T} 7$ promoter, amplified RNA (cRNA) was generated from the double-stranded cDNA template though an in-vitro transcription reaction and purified with the Affymetrix sample cleanup module. cDNA was regenerated through a random-primed reverse transcription using a dNTP mix containing dUTP. The cDNA was then fragmented by uracil-DNA-glycosylase and apurinic/apyrimidinic endonuclease 1 and endlabeled by terminal transferase reaction incorporating a biotinylated dideoxynucleotide. Fragmented endlabeled cDNA was hybridized to the GeneChip ${ }^{\circledR}$ Mouse Gene $1.0 \mathrm{ST}$ arrays for 16 hours at $45^{\circ} \mathrm{C}$ and $60 \mathrm{rpm}$ as described in the GeneChip Whole Transcript Sense Target Labeling Assay Manual (Affymetrix). After hybridization, the chips were stained and washed in a Genechip Fluidics Station 450 (Affymetrix) and scanned by using a GeneChip ${ }^{\circledR}$ Scanner 3000 7G (Affymetrix). The image data was extracted through Affymetrix Command Console software1.1. Expression data were generated by Affymetrix Expression Console software version1.1. For the normalization, Robust Multi-Average algorithm implemented in Affymetrix Expression Console software was used. All experiments were performed triplicate. The data discussed in this publication have been deposited in NCBI's Gene Expression Omnibus [50] and are accessible through GEO Series accession number GSE95742 (https://www. ncbi.nlm.nih.gov/geo/query/acc.cgi? acc=GSE95742).

\section{Histologic analysis}

Mice were treated with anti-C5 antibody $(10 \mu \mathrm{g} / 1$ $\mu \mathrm{L}$ PBS $)$ via intravitreal administration $(n=6)$. At 7 days after the injection, the enucleated eyes were fixed in $4 \%$ paraformaldehyde and embedded in paraffin. Then, 4- $\mu \mathrm{m}$-thickness paraffin sections were deparaffinized and hydrated by sequential immersion in xylene substitute and graded ethyl alcohol solutions. To investigate the histologic toxicity of anti-C5 antibody, H\&E-stained slides were evaluated to measure the ratio of the retinal thickness from the internal limiting membrane to the inner nuclear layer to that from the internal limiting membrane to the outer nuclear layer [51].

\section{ELISA for the measurement of cleaved caspase-3}

ELISA was performed with a kit (cat. no. DYC8352, R\&D) for the measurement of cleaved caspase- 3 in extracted proteins from the retina according to the manufacturer's instructions.

\section{Cell viability assay}

bEnd.3 cells in 96-well plates were treated with varying concentrations of anti-C5 antibody (1-1,000 ng/ $\mathrm{mL}$ ). At 48 hours after the treatment, the reagent from EZ-Cytox Cell Viability Assay Kit (Itsbio) was applied to each well. After 2 hours of additional incubation, the absorbance at $450 \mathrm{~nm}$ was measured using the microplate reader. These results were confirmed by direct cell counting with methylene blue staining.

\section{Statistical analysis}

All statistical analyses were performed using GraphPad Prism 5 (GraphPad). Mean values and SEM were shown in figures. Specific $P$-values and statistical methods were provided in figure legends.

\section{ACKNOWLEDGMENTS}

This study was supported by the Pioneer Research Program of the National Research Foundation of Korea/ Ministry of Education, Science and Technology (20120009544 to Je.H.K.), the Bio \& Medical Technology Development Program of the National Research Foundation funded by the Korean government, MSIP (NRF-2015M3A9E6028949 to Je.H.K. and NRF2012M3A9A9055121 to J.C.), the Development of Platform Technology for Innovative Medical Measurements Program from the Korea Research Institute of Standards and Science (KRISS-2016-16011064 to Je.H.K), and the Interdisciplinary Research Initiatives Program from College of Engineering and College of Medicine, Seoul National University (800-2016-0082 to Je.H.K.).

\section{CONFLICTS OF INTEREST}

The authors declare no conflicts of interest. 


\section{REFERENCES}

1. Jager RD, Mieler WF, Miller JW. Age-related macular degeneration. N Engl J Med. 2008; 358:2606-2617.

2. Troutbeck R, Al-Qureshi S, Guymer RH. Therapeutic targeting of the complement system in age-related macular degeneration: a review. Clin Experiment Ophthalmol. 2012; 40:18-26.

3. Hageman GS, Anderson DH, Johnson LV, Hancox LS, Taiber AJ, Hardisty LI, Hageman JL, Stockman HA, Borchardt JD, Gehrs KM, Smith RJ, Silvestri G, Russell SR, et al. A common haplotype in the complement regulatory gene factor $\mathrm{H}(\mathrm{HF} 1 / \mathrm{CFH})$ predisposes individuals to agerelated macular degeneration. Proc Natl Acad Sci USA. 2005; 102:7227-7232.

4. Klein RJ, Zeiss C, Chew EY, Tsai JY, Sackler RS, Haynes C, Henning AK, SanGiovanni JP, Mane SM, Mayne ST, Bracken MB, Ferris FL, Ott J, et al. Complement factor $\mathrm{H}$ polymorphism in age-related macular degeneration. Science. 2005; 308:385-389.

5. Maller JB, Fagerness JA, Reynolds RC, Neale BM, Daly MJ, Seddon JM. Variation in complement factor 3 is associated with risk of age-related macular degeneration. Nat Genet. 2007; 39:1200-1201.

6. Gold B, Merriam JE, Zernant J, Hancox LS, Taiber AJ, Gehrs K, Cramer K, Neel J, Bergeron J, Barile GR, Smith RT, Hageman GS, Dean M, et al, and AMD Genetics Clinical Study Group. Variation in factor B (BF) and complement component 2 (C2) genes is associated with age-related macular degeneration. Nat Genet. 2006; 38:458-462.

7. Morgan BP, Harris CL. Complement, a target for therapy in inflammatory and degenerative diseases. Nat Rev Drug Discov. 2015; 14:857-877.

8. Nozaki M, Raisler BJ, Sakurai E, Sarma JV, Barnum SR, Lambris JD, Chen Y, Zhang K, Ambati BK, Baffi JZ, Ambati J. Drusen complement components C3a and C5a promote choroidal neovascularization. Proc Natl Acad Sci USA. 2006; 103:2328-2333.

9. Mullins RF, Russell SR, Anderson DH, Hageman GS. Drusen associated with aging and age-related macular degeneration contain proteins common to extracellular deposits associated with atherosclerosis, elastosis, amyloidosis, and dense deposit disease. FASEB J. 2000; $14: 835-846$

10. Johnson LV, Ozaki S, Staples MK, Erickson PA, Anderson DH. A potential role for immune complex pathogenesis in drusen formation. Exp Eye Res. 2000; 70:441-449.

11. Reynolds R, Hartnett ME, Atkinson JP, Giclas PC, Rosner B, Seddon JM. Plasma complement components and activation fragments: associations with age-related macular degeneration genotypes and phenotypes. Invest Ophthalmol Vis Sci. 2009; 50:5818-5827.

12. Lechner J, Chen M, Hogg RE, Toth L, Silvestri G, Chakravarthy U, Xu H. Higher plasma levels of complement
$\mathrm{C} 3 \mathrm{a}, \mathrm{C} 4 \mathrm{a}$ and $\mathrm{C} 5 \mathrm{a}$ increase the risk of subretinal fibrosis in neovascular age-related macular degeneration: Complement activation in AMD. Immun Ageing. 2016; 13:4.

13. Wolf-Schnurrbusch UE, Hess R, Jordi F, Stuck AK, Sarra GM, Wolf S, Enzmann V. Detection of Chlamydia and complement factors in neovascular membranes of patients with age-related macular degeneration. Ocul Immunol Inflamm. 2013; 21:36-43.

14. Williams MA, McKay GJ, Chakravarthy U. Complement inhibitors for age-related macular degeneration. Cochrane Database Syst Rev. 2014; 1:CD009300.

15. Ricklin D, Lambris JD. Compstatin: A Complement Inhibitor on its Way to Clinical Application. Adv Exp Med Biol. 2008; 632:273-292.

16. Jore MM, Johnson S, Sheppard D, Barber NM, Li YI, Nunn MA, Elmlund H, Lea SM. Structural basis for therapeutic inhibition of complement C5. Nat Struct Mol Biol. 2016; 23:378-386.

17. Krisinger MJ, Goebeler V, Lu Z, Meixner SC, Myles T, Pryzdial EL, Conway EM. Thrombin generates previously unidentified C5 products that support the terminal complement activation pathway. Blood. 2012; 120:1717-1725.

18. Leung LL, Morser J. Plasmin as a complement C5 convertase. EBioMedicine. 2016; 5:20-21.

19. Giles JL, Choy E, van den Berg C, Morgan BP, Harris CL. Functional analysis of a complement polymorphism (rs17611) associated with rheumatoid arthritis. J Immunol. 2015; 194:3029-3034.

20. Nishimura J, Yamamoto M, Hayashi S, Ohyashiki K, Ando K, Brodsky AL, Noji H, Kitamura K, Eto T, Takahashi T, Masuko M, Matsumoto T, Wano Y, et al. Genetic variants in C5 and poor response to eculizumab. N Engl J Med. 2014; 370:632-639.

21. Lambert V, Lecomte J, Hansen S, Blacher S, Gonzalez ML, Struman I, Sounni NE, Rozet E, de Tullio P, Foidart JM, Rakic JM, Noel A. Laser-induced choroidal neovascularization model to study age-related macular degeneration in mice. Nat Protoc. 2013; 8:2197-2211.

22. Kim JH, Kim JH, Yu YS, Park KH, Kang HJ, Lee HY, Kim KW. Antiangiogenic effect of deguelin on choroidal neovascularization. J Pharmacol Exp Ther. 2008; 324:643-647.

23. Fukuoka Y, Strainic M, Medof ME. Differential cytokine expression of human retinal pigment epithelial cells in response to stimulation by C5a. Clin Exp Immunol. 2003; 131:248-253.

24. Hu M, Liu B, Jawad S, Ling D, Casady M, Wei L, Nussenblatt RB. C5a contributes to intraocular inflammation by affecting retinal pigment epithelial cells and immune cells. Br J Ophthalmol. 2011; 95:1738-1744.

25. Grossniklaus HE, Ling JX, Wallace TM, Dithmar S, Lawson DH, Cohen C, Elner VM, Elner SG, Sternberg P Jr. Macrophage and retinal pigment epithelium expression of 
angiogenic cytokines in choroidal neovascularization. Mol Vis. 2002; 8:119-126.

26. Jawad S, Liu B, Li Z, Katamay R, Campos M, Wei L, Sen HN, Ling D, Martinez Estrada F, Amaral J, Chan CC, Fariss R, Gordon S, Nussenblatt RB. The role of macrophage class a scavenger receptors in a laser-induced murine choroidal neovascularization model. Invest Ophthalmol Vis Sci. 2013; 54:5959-5970.

27. Tsutsumi-Miyahara C, Sonoda KH, Egashira K, Ishibashi M, Qiao H, Oshima T, Murata T, Miyazaki M, Charo IF, Hamano S, Ishibashi T. The relative contributions of each subset of ocular infiltrated cells in experimental choroidal neovascularisation. Br J Ophthalmol. 2004; 88:1217-1222.

28. Sakurai E, Anand A, Ambati BK, van Rooijen N, Ambati J. Macrophage depletion inhibits experimental choroidal neovascularization. Invest Ophthalmol Vis Sci. 2003; 44:3578-3585.

29. Liu J, Copland DA, Horie S, Wu WK, Chen M, Xu Y, Paul Morgan B, Mack M, Xu H, Nicholson LB, Dick AD. Myeloid cells expressing VEGF and arginase-1 following uptake of damaged retinal pigment epithelium suggests potential mechanism that drives the onset of choroidal angiogenesis in mice. PLoS One. 2013; 8:e72935.

30. He L, Marneros AG. Macrophages are essential for the early wound healing response and the formation of a fibrovascular scar. Am J Pathol. 2013; 182:2407-2417.

31. He L, Marneros AG. Doxycycline inhibits polarization of macrophages to the proangiogenic M2-type and subsequent neovascularization. J Biol Chem. 2014; 289:8019-8028.

32. Jo DH, Kim JH, Kim JH. How to overcome retinal neuropathy: the fight against angiogenesis-related blindness. Arch Pharm Res. 2010; 33:1557-1565.

33. Kurihara T, Westenskow PD, Bravo S, Aguilar E, Friedlander M. Targeted deletion of Vegfa in adult mice induces vision loss. J Clin Invest. 2012; 122:4213-4217.

34. Rohrer B, Coughlin B, Kunchithapautham K, Long Q, Tomlinson S, Takahashi K, Holers VM. The alternative pathway is required, but not alone sufficient, for retinal pathology in mouse laser-induced choroidal neovascularization. Mol Immunol. 2011; 48:e1-8.

35. Cortright DN, Meade R, Waters SM, Chenard BL, Krause JE. C5a, but not C3a, increases VEGF secretion in ARPE19 human retinal pigment epithelial cells. Curr Eye Res. 2009; 34:57-61.

36. Ambati J, Anand A, Fernandez S, Sakurai E, Lynn BC, Kuziel WA, Rollins BJ, Ambati BK. An animal model of age-related macular degeneration in senescent Ccl-2- or Ccr-2-deficient mice. Nat Med. 2003; 9:1390-1397.

37. Czermak BJ, Sarma V, Bless NM, Schmal H, Friedl HP, Ward PA. In vitro and in vivo dependency of chemokine generation on C5a and TNF-alpha. J Immunol. 1999; 162:2321-2325.

38. Skeie JM, Fingert JH, Russell SR, Stone EM, Mullins RF. Complement component C5a activates ICAM-1 expression on human choroidal endothelial cells. Invest Ophthalmol Vis Sci. 2010; 51:5336-5342.

39. Albrecht EA, Chinnaiyan AM, Varambally S, Kumar-Sinha C, Barrette TR, Sarma JV, Ward PA. C5a-induced gene expression in human umbilical vein endothelial cells. Am J Pathol. 2004; 164:849-859.

40. Sica A, Mantovani A. Macrophage plasticity and polarization: in vivo veritas. J Clin Invest. 2012; 122:787-795.

41. Brockmann C, Brockmann T, Dege S, Busch C, Kociok N, Vater A, Klussmann S, Strauss O, Joussen AM. Intravitreal inhibition of complement $\mathrm{C} 5 \mathrm{a}$ reduces choroidal neovascularization in mice. Graefes Arch Clin Exp Ophthalmol. 2015; 253:1695-1704.

42. Coughlin B, Schnabolk G, Joseph K, Raikwar H, Kunchithapautham K, Johnson K, Moore K, Wang Y, Rohrer B. Connecting the innate and adaptive immune responses in mouse choroidal neovascularization via the anaphylatoxin C5a and gammadeltaT-cells. Sci Rep. 2016; 6:23794.

43. Bora NS, Kaliappan S, Jha P, Xu Q, Sohn JH, Dhaulakhandi DB, Kaplan HJ, Bora PS. Complement activation via alternative pathway is critical in the development of laserinduced choroidal neovascularization: role of factor B and factor H. J Immunol. 2006; 177:1872-1878.

44. Thomas TC, Rollins SA, Rother RP, Giannoni MA, Hartman SL, Elliott EA, Nye SH, Matis LA, Squinto SP, Evans MJ. Inhibition of complement activity by humanized anti-C5 antibody and single-chain Fv. Mol Immunol. 1996; 33:1389-1401.

45. Volk AL, Hu FJ, Berglund MM, Nordling E, Stromberg P, Uhlen M, Rockberg J. Stratification of responders towards eculizumab using a structural epitope mapping strategy. Sci Rep. 2016; 6:31365.

46. Barbas CF 3rd, Burton DR, Scott JK, Silverman GJ. Phage Display: A Laboratory Manual. New York: Cold Spring Harbor Laboratory Press; 2001.

47. Kim M, Yoon S, Lee S, Ha SA, Kim HK, Kim JW, Chung J. Gremlin-1 induces BMP-independent tumor cell proliferation, migration, and invasion. PLoS One. 2012; 7:e35100.

48. Burnette WN. "Western blotting": electrophoretic transfer of proteins from sodium dodecyl sulfate--polyacrylamide gels to unmodified nitrocellulose and radiographic detection with antibody and radioiodinated protein A. Anal Biochem. 1981; 112:195-203.

49. Kim H, Park S, Lee HK, Chung J. Application of bispecific antibody against antigen and hapten for immunodetection and immunopurification. Exp Mol Med. 2013; 45 :e43.

50. Edgar R, Domrachev M, Lash AE. Gene Expression Omnibus: NCBI gene expression and hybridization array data repository. Nucleic Acids Res. 2002; 30:207-210.

51. Kim JH, Kim C, Kim JH, Lee BJ, Yu YS, Park KH, Kim $\mathrm{KW}$. Absence of intravitreal bevacizumab-induced neuronal toxicity in the retina. Neurotoxicology. 2008; 29:1131-1135. 